\title{
sensors
}

ISSN 1424-8220

(C) 2005 by MDPI

http://www.mdpi.org/sensors

\section{Immobilization of DNA at Glassy Ccarbon Electrodes: A Critical Study of Adsorbed Layer}

\author{
M. L. Pedano and G. A. Rivas* \\ INFIQC. Departamento de Físico Química. Facultad de Ciencias Químicas. Universidad Nacional de \\ Córdoba. Ciudad Universitaria. 5000 Córdoba. Argentina
}

* Author to whom correspondence should be addressed. E-mail: grivas@fcq.unc.edu.ar

Received: 23 February 2005 / Accepted: 16 March 2005 / Published: 14 November 2005

\begin{abstract}
In this work we present a critical study of the nucleic acid layer immobilized at glassy carbon electrodes. Different studies were performed in order to assess the nature of the interaction between DNA and the electrode surface. The adsorption and electrooxidation of DNA demonstrated to be highly dependent on the surface and nature of the glassy carbon electrode. The DNA layer immobilized at a freshly polished glassy carbon electrode was very stable even after applying highly negative potentials. The electron transfer of potassium ferricyanide, catechol and dopamine at glassy carbon surfaces modified with thin (obtained by adsorption under controlled potential conditions) and thick (obtained by casting the glassy carbon surface with highly concentrated DNA solutions) DNA layers was slower than that at the bare glassy carbon electrode, although this effect was dependent on the thickness of the layer and was not charge selective. Raman experiments showed an important decrease of the vibrational modes assigned to the nucleobases residues, suggesting a strong interaction of these residues with the electrode surface. The hybridization of oligo(dG) $)_{21}$ and oligo(dC) $)_{21}$ was evaluated from the guanine oxidation signal and the reduction of the redox indicator $\mathrm{Co}(\text { phen })_{3}{ }^{3+}$. In both cases the chronopotentiometric response indicated that the compromise of the bases in the interaction of DNA with the electrode surface is too strong, preventing further hybridization. In summary, glassy carbon is a useful electrode material to detect DNA in a direct and very sensitive way, but not to be used for the preparation of biorecognition layers by direct adsorption of the probe sequence on the electrode surface for detecting the hybridization event.
\end{abstract}

Key words: DNA-biosensors, DNA adsorption, glassy carbon electrode, DNA-modified electrode, redox indicator. 


\section{Introduction}

Since the first publication about the electrochemistry of nucleic acids [1], there has been a growing interest in the development of electrochemical affinity biosensors based on the use of nucleic acids as biorecognition element. Different strategies for DNA-based biosensors preparation as well as different transduction modes have been proposed, as it was largely reviewed [2-13].

Carbon materials have been widely used for studying the adsorption and oxidation of nucleic acids. Composites electrodes like graphite paste (CPE) [14-19], screen printed (SPE) [20] and nanotubes paste (CNTPE) [21]; and solid electrodes like carbon fiber [22], glassy carbon (GCE) [2330], glassy carbon modified with nanotubes [31], graphite [32], highly oriented pyrolitic graphite [33] and boron doped diamond [34] have demonstrated to be very useful for this task.

Brabec et al. [35] studied the electrochemical behavior of DNA at carbon electrodes by using voltammetric techniques. They found that the oxidation currents are higher for smaller DNA molecules and that low-molecular weight components of DNA present in DNA samples can influence the DNA electrooxidation. Pang et al. [36] found that DNA can be strongly adsorbed on glassy carbon surfaces only if the DNA solution is evaporated to dryness on the electrode. They evaluated the presence of the nucleic acid layer from the signal of the redox indicator Co(phen) ${ }_{3}{ }^{3+}$. Oliveira Brett et al. [27-30] reported on the use of glassy carbon pretreated as a substrate for preparing DNA modified electrodes (subjected to oxidation processes) to evaluate the voltammetric behavior of nitroimidazoles. Wang, Z. et al. [37] reported on the adsorption and oxidation of denatured and double stranded DNA at glassy carbon electrodes by using differential pulse voltammetry (DPV) and "in situ" FTIR spectroelectrochemistry. They found that after accumulation of denatured calf thymus DNA, and depending on the denaturation procedure, a partly reversible voltammetric behavior is obtained and a multilayer is formed on the electrode surface.

Oliveira Brett and Matysik [38] reported the sonovoltammetric detection of all nucleobases at GCE. These results were obtained in alkaline solutions and pyrimidine concentrations ten times higher than those of purines. Recently, Oliveira Brett et al. [39] proposed the detection of all 
deoxyribonucleotides at GCE using DPV. They reported that an adequate conditioning of GCE (polishing, sonication and potentiostatic and potentiodynamic electrooxidation schemes) made it possible a better peak separation and enhancement of the oxidation currents for all the DNA bases, as well as the simultaneous detection of the oxidation of pyrimidine residues in ssDNA in phosphate buffer solutions pH 7.4.

In this work we report on a critical study about the characteristics of the DNA layer immobilized at the surface of GCE by using different techniques. The main interest was focused on the determination of the type of interaction of DNA with the electrode surface (electrostatic versus hydrophobic), as well as the compromise of the bases in this interaction.

\section{Experimental}

\subsection{Reagents}

The oligonucleotides were purchased from Life Technologies (Grand Island, New York, USA) as their ammonium salts:

Probe sequence: Oligo(dG) 21 3’-GGG GGG GGG GGG GGG GGG GGG-5’ Target sequence: Oligo (dC) ${ }_{21}$ 3'-CCC CCC CCC CCC CCC CCC CCC-5'

Double stranded calf thymus DNA (dsDNA) (activated and lyophilized, catalog number D4522) and dopamine were purchased from SIGMA (St. Louis, MO). Potassium ferricyanide and pyrocatechol were from Mallinckrodt. All other reagents were of analytical grade.

DNA stock solutions (nominally $1000 \mathrm{mg} / \mathrm{L}$ ) were prepared with TE buffer (1 x concentrate, 10 mM Tris-HCl, 1 mM EDTA, pH 8,0).

Intercalators solutions were prepared in $0.020 \mathrm{M}$ Tris-HCl buffer $\mathrm{pH} 7.00 . \mathrm{Co}(\mathrm{phen})^{3+}$ was kindly received from Prof. J. Wang.

Ultrapure water $(\rho=18 \mathrm{M} \Omega$ ) from a Millipore-MilliQ system was used for preparing all the solutions.

\subsection{Apparatus}


Constant-current chronopotentiometric experiments were performed with a TraceLab Potentiometric Stripping Unit PSU 22 (Radiometer, France) connected to a PC. According to the Trace Lab protocol, the potentials were sampled at a frequency of $30 \mathrm{kHz}$ and the derivative signal (dt/dE) versus potential (E) was recorded following baseline fitting. Voltammetric experiments were performed with an EPSILON (BAS) work-station.

The three-electrode system consisted of a $3.0 \mathrm{~mm}$ diameter working electrode, either glassy carbon (GCE, CH Instruments, Austin, TX, USA) or graphite paste electrode (gCPE); a Ag/AgCl reference electrode (BAS Model RE-5B) and a platinum wire auxiliary electrode. All potentials are referred to that reference electrode. In some cases GCEs of different origin were also used (BAS, and V-10 Carbone Lorraine) The electrodes joined the cell through holes in its Teflon cover. The graphite paste electrode was prepared by mixing in an agate mortar graphite powder (Fisher grade \# 38) (70.0 $\% \mathrm{w} / \mathrm{w})$ and mineral oil (Aldrich) $(30.0 \% \mathrm{w} / \mathrm{w})$ for $30 \mathrm{~min}$. A portion of the resulting paste was packed firmly into the cavity (3.0 mm diameter) of a Teflon tube. The electric contact was established via a stainless steel screw. A new surface was obtained by smoothing the electrode onto a weighing paper. The glassy carbon electrode was cleaned by hand polishing for 2 minutes with $0.30 \mu \mathrm{ml}_{2} \mathrm{O}_{3}$ slurry. After that it was exhaustively rinsed and sonicated in ultrapure water for $5 \mathrm{~s}$.

A magnetic stirrer was used during the DNA accumulation, hybridization and redox indicator interaction steps.

Raman experiments were performed with a Raman Spectrometer Le T64000 at Joseph Fourier University (Grenoble, France).

\subsection{Procedure}

\subsubsection{Electrochemical experiments:}

\subsection{1.a. Nucleic acid adsorption and electrooxidation:}

Consisted of:

Nucleic acid immobilization: Polished GCE or gCPE were immersed in a stirred $0.200 \mathrm{M}$ acetate buffer pH 5.00 containing DNA while holding the potential at $0.200 \mathrm{~V}$ for a given time. 
Washing of the DNA-modified electrode before the medium exchange with $0.200 \mathrm{M}$ acetate buffer solution pH 5.00 for 5 seconds.

Chronopotentiometric transduction: Performed in a $0.200 \mathrm{M}$ acetate buffer solution pH 5.00 by applying a constant current of $8.0 \mu \mathrm{A}$ from an initial potential of $0.500 \mathrm{~V}$. The anodic peak at around $1.0 \mathrm{~V}$, corresponding to the guanine oxidation, was used as the analytical signal.

\subsection{1.b. Hybridization detection:}

2.3.1.b.I. From the quanine oxidation signal: The detection sequence consisted of the following steps: probe immobilization (accumulation or adsorption), hybridization and chronopotentiometric transduction.

Probe immobilization: Polished GCE or gCPE were immersed in a stirred $0.200 \mathrm{M}$ acetate buffer solution $\mathrm{pH} 5.00$ containing ssDNA (probe sequence) while holding the potential at $0.200 \mathrm{~V}$ for a given time to ensure full surface coverage.

Washing of the ssDNA-modified electrode with $0.020 \mathrm{M}$ phosphate buffer solution pH $7.40+0.050 \mathrm{M}$ $\mathrm{NaCl}$ for 5 seconds.

Hybridization: The probe-modified GCE or gCPE were immersed in a stirred $0.020 \mathrm{M}$ phosphate buffer $\mathrm{pH} 7.40$ containing $0.500 \mathrm{M} \mathrm{NaCl}$ and the complementary sequence (target sequence), at a constant potential of $0.200 \mathrm{~V}$ for a given time.

Washing of the electrode before the medium exchange with $0.200 \mathrm{M}$ acetate buffer solution $\mathrm{pH} 5.00$ for 5 seconds.

Chronopotentiometric transduction: Performed in a $0.200 \mathrm{M}$ acetate buffer solution pH 5.00 by applying a constant current of $8.0 \mu \mathrm{A}$ from an initial potential of $0.500 \mathrm{~V}$. The anodic peak at around 1.0 V, corresponding to the guanine oxidation, was used as the analytical signal.

2.3.1.b.II. From the signal of a redox indicator: The detection sequence consisted of the following steps: probe immobilization (accumulation or adsorption), hybridization, redox indicator interaction (redox indicator accumulation) and chronopotentiometric transduction. 
Probe immobilization: Polished GCE or gCPE were immersed in a stirred $0.200 \mathrm{M}$ acetate buffer solution pH 5.00 containing the DNA probe while holding the potential at $0.200 \mathrm{~V}$ for a given time to ensure full coverage of the surface.

Washing of the probe-modified electrode with $0.020 \mathrm{M}$ phosphate buffer solution pH $7.40+0.050 \mathrm{M}$ $\mathrm{NaCl}$ for 5 seconds.

Hybridization: The probe-modified GCE or gCPE were immersed in a stirred $0.020 \mathrm{M}$ phosphate buffer solution $\mathrm{pH} 7.40$ containing $0.500 \mathrm{M} \mathrm{NaCl}$ and the complementary sequence (target sequence), at a constant potential of $0.500 \mathrm{~V}$ for a given time.

Washing of the double helix-modified electrode with a $0.020 \mathrm{M}$ Tris-HCl buffer solution $\mathrm{pH} 7.00$ for 5 seconds.

Redox indicator interaction: Performed by immersion of the modified electrode in a 0.020 M Tris-

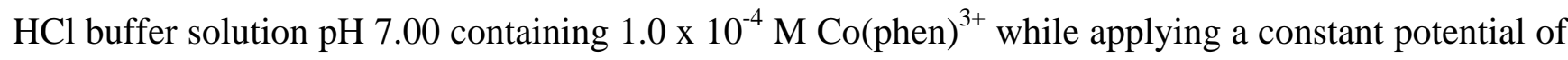
$0.500 \mathrm{~V}$ for $2.0 \mathrm{~min}$.

Washing of the electrode before the medium exchange with a $0.020 \mathrm{M}$ Tris- $\mathrm{HCl}$ buffer solution $\mathrm{pH}$ 7.00 for 5 seconds.

Chronopotentiometric transduction: Performed in a $0.020 \mathrm{M}$ Tris-HCl buffer solution $\mathrm{pH} 7.00$ by applying a constant current of $-6.0 \mu \mathrm{A}$ with an initial potential of $0.500 \mathrm{~V}$. The cathodic peak at around $0.15 \mathrm{~V}$, corresponding to the reduction of the redox indicator, was used as the analytical signal.

Repetitive measurements were carried out by polishing the surface of GCE or gCPE and repeating the above assay. All experiments were performed at room temperature.

\subsubsection{Raman experiments}

The reference spectrum of DNA was taken from solid calf thymus dsDNA. Samples obtained by immobilization of DNA solutions, were prepared in two ways. In one case, by casting the glassy carbon disk (CH Instruments or Alfa AEsar) with $10 \mu \mathrm{L}$ of 1000 ppm dsDNA solution and waiting until dryness. In the other case, it was obtained by depositing the nucleic acids under potential controlled conditions ensuring full coverage of the surface. In the latter, the dsDNA was deposited at 
$0.200 \mathrm{~V}$ from a $10.0 \mathrm{ppm}$ solution for $5.0 \mathrm{~min}$, while the oligo(dG) $)_{21}$ was accumulated from a $2 \mathrm{ppm}$ solution for $3.0 \mathrm{~min}$. Some experiments were performed once the DNA layer was oxidized by performing a chronopotentiometric stripping between 500 and $1250 \mathrm{mV}$ at a constant current of $8.0 \mu \mathrm{A}$.

\section{Results and Discussion}

Figure 1 shows the chronopotentiometric signals obtained in a $0.200 \mathrm{M}$ acetate buffer solution pH 5.00 for 0.5 ppm oligo(dG) $)_{21}$ after $30 \mathrm{sec}(\mathrm{a})$ and $3 \mathrm{~min}$ (b) accumulation and for $1.0 \mathrm{ppm}$ dsDNA after 15 min accumulation (c) at $0.200 \mathrm{~V}$. In all cases a clear signal is obtained at around $1.0 \mathrm{~V}$ due to the oxidation of guanine residues. The excellent capability of the instrument used to perform the chronopotentiometric analysis, that includes a very efficient base line correction and signal filtering, has allowed us to obtain very well defined signals even at such positive potentials close to the oxygen evolution.

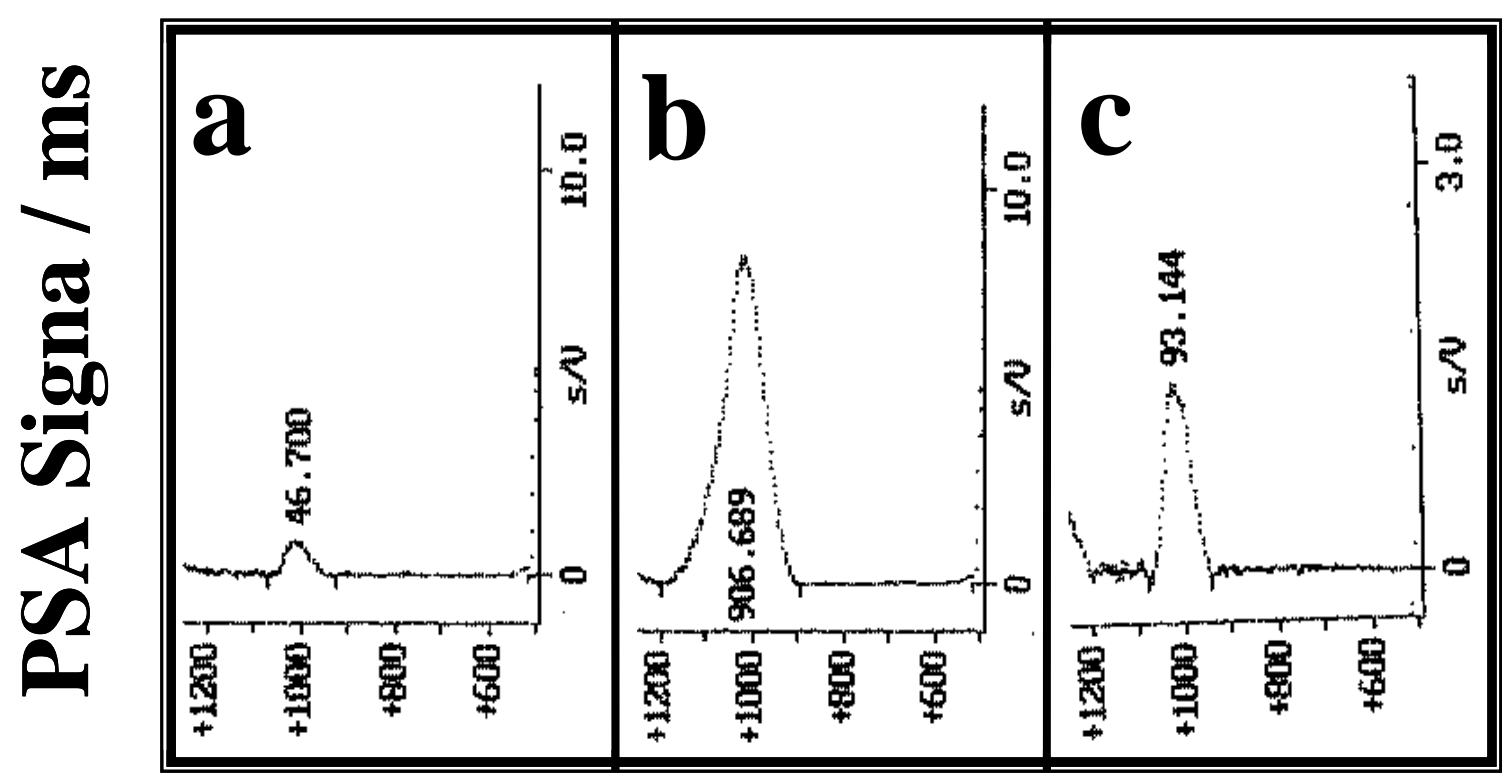

\section{Potential / mV}

Figure 1. Chronopotentiograms obtained in a $0.200 \mathrm{M}$ acetate buffer solution $\mathrm{pH} 5.00$ for $0.5 \mathrm{ppm}$ oligo(dG) $)_{21}$ after $30 \mathrm{sec}$ (a) and $3 \mathrm{~min}$ (b) accumulation, and for $1.0 \mathrm{ppm}$ dsDNA after 15 min accumulation (c) at $0.200 \mathrm{~V}$. Stripping conditions: initial potential: $0.500 \mathrm{~V}$; current: $8.0 \mu \mathrm{A}$. 
In the following sections we discuss about the characteristics of the DNA layer immobilized at glassy carbon surfaces from different points of view.

We evaluate the interaction of different redox couples with the DNA layer from their voltammetric behavior at bare and dsDNA-modified-glassy carbon electrodes. Catechol, potassium ferricyanide and dopamine ( $\mathrm{pk}_{\mathrm{a}}=8.87$ ), were used as redox markers. At the working conditions these compounds present neutral, negative and positive charges, respectively. The dsDNA was immobilized at GCE in two ways, by adsorption under controlled potential conditions (1.0, 5.0, and 10.0 min at $0.200 \mathrm{~V}$ from a $30.0 \mathrm{ppm}$ dsDNA solution) and by casting the GCE with $5 \mu \mathrm{L}$ of a $4900 \mathrm{ppm}$ dsDNA solution. Figure 2 shows the voltammetric response for $5.0 \times 10^{-4} \mathrm{M}$ potassium ferricyanide (A), catechol (B) and dopamine (C) at bare GCE (black) and at dsDNA-modified-GCE obtained by adsorption from a 30.0 ppm dsDNA solution for 1.0, 5.0 and 10.0 min (blue, green and red, respectively). In the presence of these thin layers of dsDNA, just a small decrease in the reduction currents of potassium ferricyanide and oxidation currents of catechol and dopamine was obtained. These changes were more evident using GCEs modified by immobilizing dsDNA for longer times, although no much difference was observed between GCE modified with DNA after 5.0 and 10.0 min adsorption. For instance, at GCE modified by adsorbing dsDNA for $5 \mathrm{~min}$, the reduction current for ferricyanide decreases $15.3 \%$, while those for catechol and dopamine decrease $25.9 \%$ and $21.4 \%$, respectively. An increase in the peak potentials separation for all the redox markers was also obtained, indicating that the DNA layer makes more difficult the electron transfer. The peak potential separation increased by 51, 83 and $156 \mathrm{mV}$ for potassium ferricyanide, catechol and dopamine, respectively. Another interesting fact is that once the DNA layer was oxidized, in general, the oxidation and reduction currents were slightly smaller than those obtained at dsDNA-GCE without oxidation, while peak potentials separations increase just a little. 


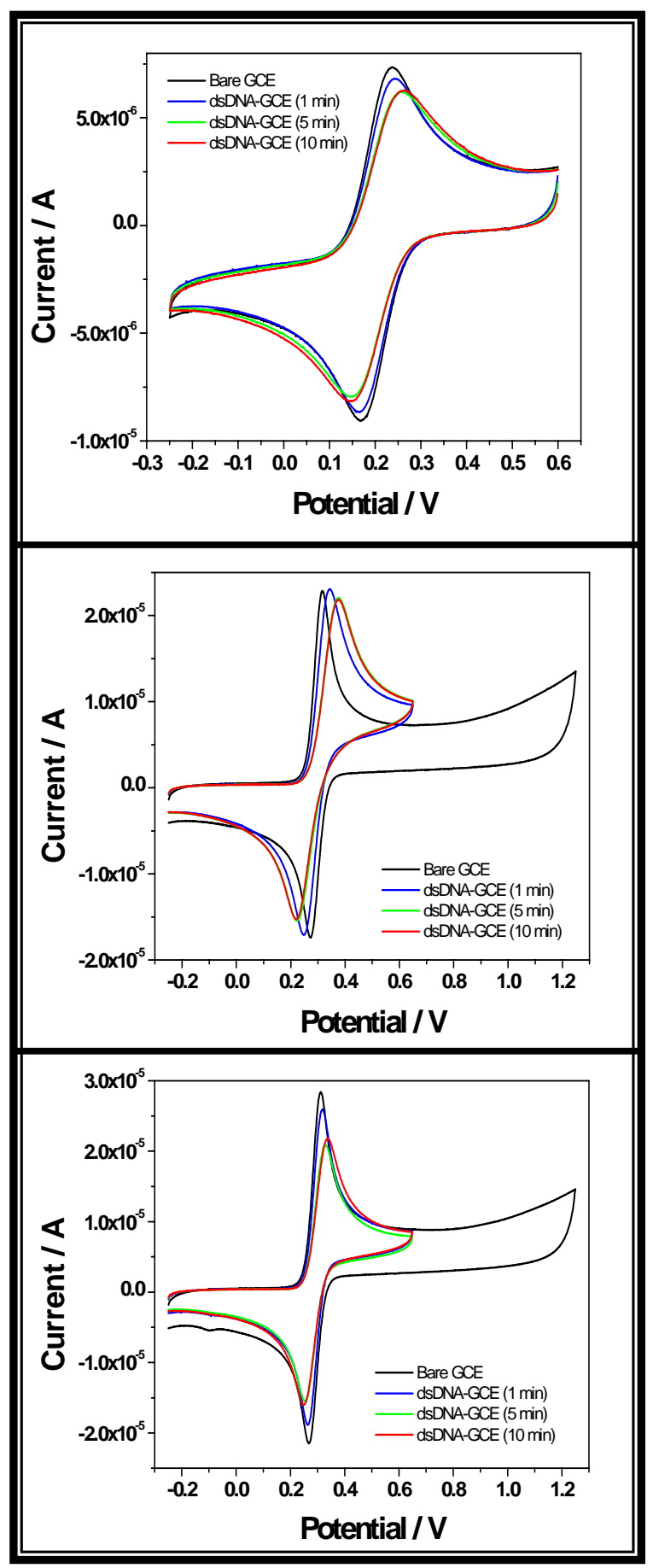

Figure 2. Cyclic voltammograms for $5.0 \times 10^{-4} \mathrm{M}$ potassium ferricyanide (A), catechol (B) and dopamine (C) at bare GCE (black) and at dsDNA-modified-GCE obtained by adsorption from a 30.0 ppm dsDNA solution for $1.0 \mathrm{~min}$ (blue), $5.0 \mathrm{~min}$ (green) and $10.0 \mathrm{~min}$ (red). Supporting electrolyte: $0.200 \mathrm{M}$ acetate buffer solution $\mathrm{pH}$ 5.0. Scan rate: $0.100 \mathrm{~V} / \mathrm{s}$.

A more drastic effect on the voltammetric behavior of the redox markers was obtained when the GCE was modified by a thick layer of DNA prepared by adsorption of $5 \mu \mathrm{L} 4900$ ppm dsDNA until dryness. Figure 3 shows the voltammetric profiles for potassium ferricyanide (A), catechol (B) 
and dopamine (C) at bare GCE (black) and at dsDNA-modified-GCE (one cycle without oxidizing the DNA (red), another cycle during the DNA oxidation (green) and a last cycle after DNA oxidation (blue)). In the presence of the DNA layer the reduction current for potassium ferricyanide and oxidation currents for dopamine and catechol decreased around $80 \%$. The peak potential separation showed a large increase in the case of catechol $(186 \mathrm{mV})$ and dopamine $(196 \mathrm{mV})$ and a small increase in the case of potassium ferricyanide $(24 \mathrm{mV})$. Another important aspect to be considered is the change in the currents and peak potential separation with the number of cycles. After the large decrease in peak currents observed for the cycle one, a gradual increase was observed in the consecutive ones in all cases. Once the DNA was electrooxidized, the signal for potassium ferricyanide decreased, while those for the other two compounds, slightly increased.

In summary, these results indicate that the DNA layer obtained by both of the two procedures employed forms some kind of islands leaving channels or uncovered areas that allow the redox markers reach the electrode surface and perform the electrons exchange. It is clear that both types of DNA layers work like a non-charge selective physical barrier for the diffusion of the redox markers, although it does not completely block their diffusion towards the GC surface.

Regarding the different increase in the peak potential separation for the three redox markers at the GCE modified with thick DNA films, it can be attributed to some interaction of catechol and dopamine with the DNA immobilized close to the electrode surface. Once these aromatic compounds reach the electrode surface through the pores of the DNA layer, they could establish hydrophobic interactions with the nucleobases located close to the electrode surface through the $\pi$ system. Since potassium ferricyanide does not have aromatic structure, it is not able to establish the same kind of interaction with DNA as catechol and dopamine and the peak potential separation change is smaller. The increase in the currents observed in the second cycle can be assigned to a reorganization of the DNA layer that allows more redox marker molecules reach the electrode surface. At the thin layers, a similar behavior is obtained, although the changes are not as important as in the case of a GCE modified with a thick DNA layer. 


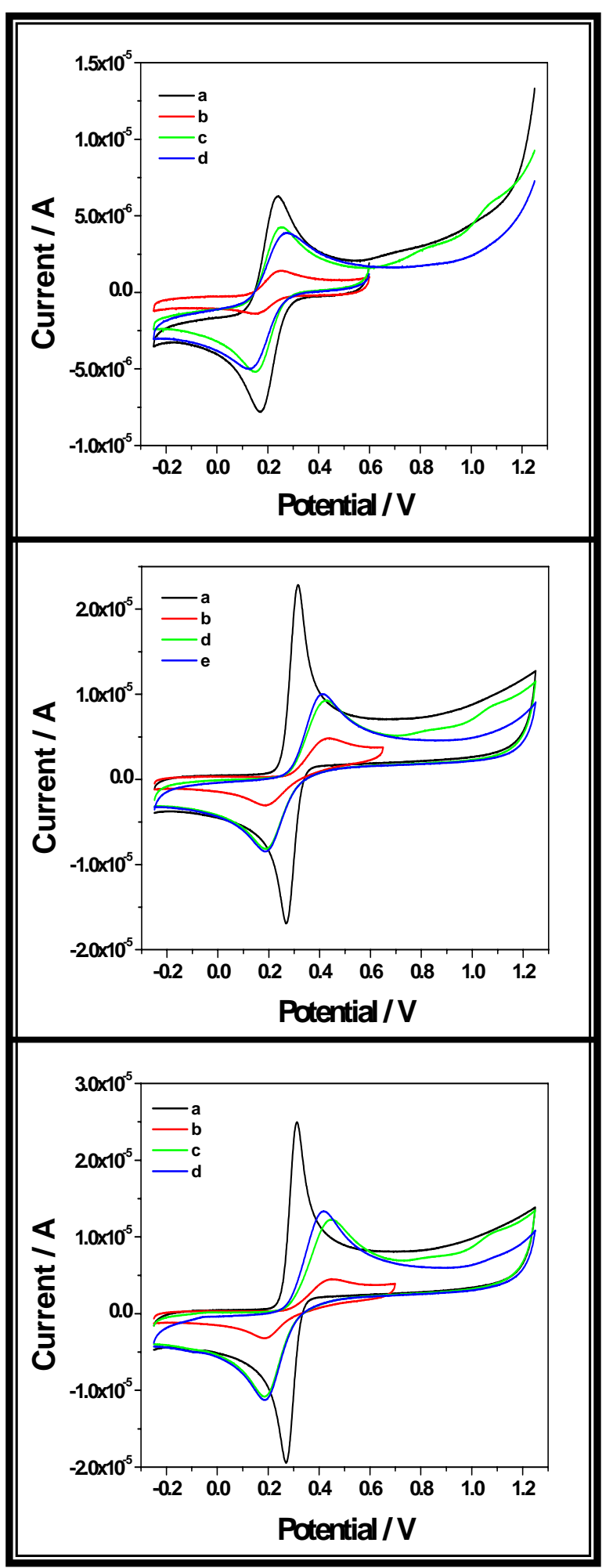

Figure 3. Cyclic voltammograms for $5.0 \times 10^{-4} \mathrm{M}$ potassium ferricyanide (A), catechol (B) and dopamine (C) at bare GCE (black) and at dsDNA-modified-GCE obtained by casting the electrode with $5.0 \mu \mathrm{L}$ of a $4900 \mathrm{ppm}$ dsDNA solution until dryness (one cycle, without oxidizing the DNA (red); another cycle, during the DNA oxidation (green) and a last cycle, after DNA oxidation (blue)). Other conditions as in Figure 2.

The state of the glassy carbon surface is another important variable for the adsorption of DNA. In fact, we have previously shown [23] that our glassy carbon electrode treated under different 
conditions like direct exposure to air, potentiodynamic and potentiostatic treatments in sulfuric acid, sodium hydroxide, phosphate and acetate buffers gave a response considerably smaller than that obtained at the freshly polished electrode. Therefore, the adsorption and electrooxidation of nucleic acids is more difficult at this pretreated glassy carbon surface, at variance with graphite paste electrode, where a pretreatment is necessary to obtain a good guanine oxidation signal. The origin (procedence) of the glassy carbon has also demonstrated to be an important variable. We have evaluated the adsorption and electrooxidation of dsDNA at three different electrodes: $\mathrm{CH}$ Instruments, BAS (having the same geometric area) and V-10 Carbone-Lorraine (with a considerably larger geometric area). The response obtained at the $\mathrm{CH}$ and BAS glassy carbon electrodes was similar. On the contrary, no response was obtained at the V-10 Carbone-Lorraine glassy carbon electrode even after covering the electrode with $5 \mu \mathrm{L}$ of a $4900 \mathrm{ppm}$ solution. Therefore, the different content of oxygenated functions, related to the preparation conditions of glassy carbon, results very important for further adsorption and electrooxidation of nucleic acids. A similar behavior was reported [22] in the case of carbon fiber electrodes, where very different guanine oxidation signals were obtained after nucleic acids adsorption and electrooxidation depending on the origin of the fiber.

It is known that the adsorption of oligo and polynucleotides on the surface of glassy carbon is independent on the adsorption potential between -0.30 and $0.50 \mathrm{~V}$ in acetate buffer solution, suggesting an interaction mainly hydrophobic with the surface [23]. To have another evidence of this behavior, we evaluated the effect of applying different potentials (called “desorption potential”) on the nucleic acid layer immobilized at the surface of glassy carbon electrodes. The DNA layer was adsorbed from a $0.200 \mathrm{M}$ acetate buffer solution containing $5.00 \mathrm{ppm}$ dsDNA for $5.00 \mathrm{~min}$ at $0.200 \mathrm{~V}$ (dsDNA-GCE). After that, different potentials, from $0.50 \mathrm{~V}$ to $-1.90 \mathrm{~V}$, were applied to the dsDNAGCE for 2 min in a stirred $0.200 \mathrm{M}$ acetate buffer solution $\mathrm{pH} 5.00$ and the chronopotentiometric signal was obtained in acetate buffer after medium exchange. Figure 4 shows the choronopotentiometric guanine oxidation signal as a function of the desorption potentials. Even for potentials as negative as $-1.70 \mathrm{~V}$, there was no change in the guanine oxidation signal compared to the 
control, indicating that the DNA layer remains adsorbed at the surface. It was necessary to apply very negative potentials to release a small fraction of the DNA immobilized at the glassy carbon electrode. In fact, after applying $-1.90 \mathrm{~V}$, the guanine oxidation signal decreased just $25 \%$. These results are another evidence of a minor electrostatic contribution. Similar experiments performed with graphite paste electrode modified with dsDNA, where the interaction is mainly electrostatic, showed a decrease in the guanine oxidation signal of around $90 \%$ after applying $-1.20 \mathrm{~V}$ for $2 \min$ [40].

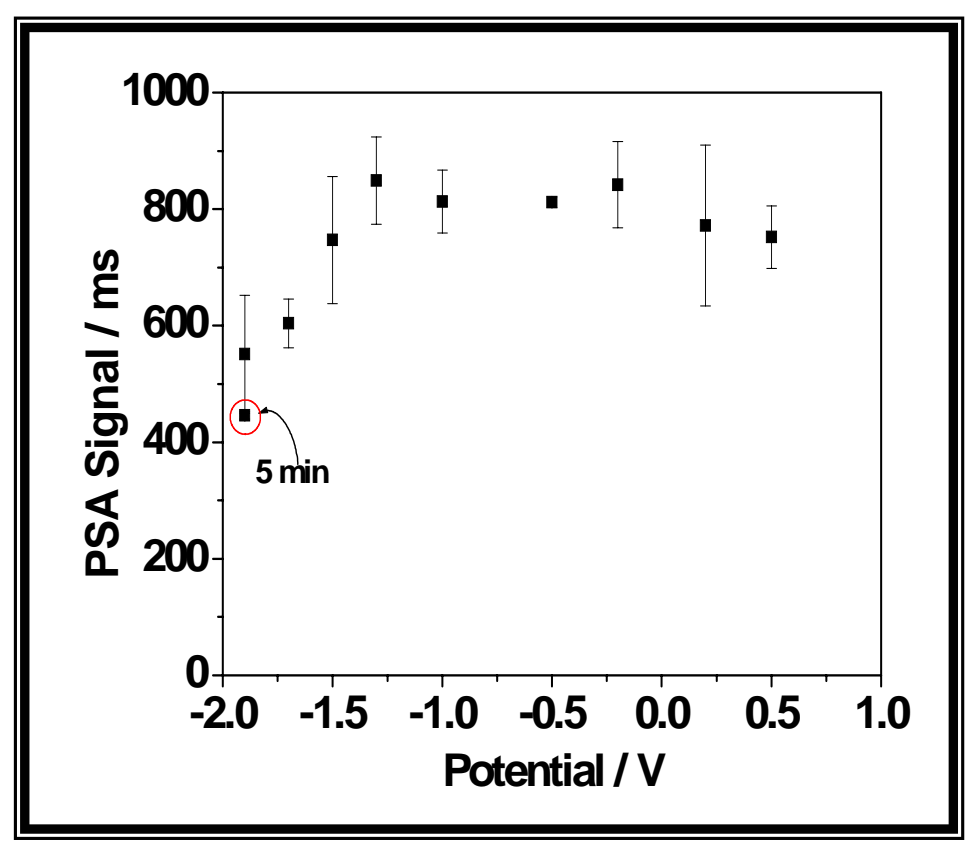

Figure 4. Chronopotentiometric guanine oxidation signal as a function of the desorption potential applied to the DNA immobilized layer. Conditions for DNA immobilization: $5.0 \mathrm{~min}$ at $0.200 \mathrm{~V}$ from a $5.00 \mathrm{ppm}$ dsDNA solution. The "desorption potential" was applied for $2.0 \mathrm{~min}$ (with the exception to the point indicated in the plot as $5 \mathrm{~min}$ ) under stirring in a $0.200 \mathrm{M}$ acetate buffer solution $\mathrm{pH}$ 5.00. Stripping conditions: initial potential: $0.500 \mathrm{~V}$; current: $8.0 \mu \mathrm{A}$; solution: $0.200 \mathrm{M}$ acetate buffer $\mathrm{pH} 5.00$.

Raman experiments were also performed in order to evaluate the type of interaction between nucleic acids and glassy carbon surface. The oligo and polinucleotides were immobilized either by casting the glassy carbon electrode with $10 \mu \mathrm{L}$ of 1000 ppm dsDNA solution or by adsorbing oligo and polynucleotides under controlled-potential conditions from solutions of different concentrations. Solid dsDNA, taken as reference, presented Raman lines in the region of (700-1700) $\mathrm{cm}^{-1}$ that corresponds mainly to the symmetric stretching of the sugar-phosphate backbone $\left(700-1100 \mathrm{~cm}^{-1}\right)$ and to the 
breathing and stretching of the bases (600-800 and 1200-1400 $\mathrm{cm}^{-1}$, respectively) [41-42]. The spectra for dsDNA immobilized at the glassy carbon (in any of the immobilization procedures) showed less bands than that for solid dsDNA. There was a shifting in the frequencies of some bands and several disappeared as a consequence of the interaction and orientation of the macromolecule with the electrode surface. This effect is more pronounced if the immobilization of DNA is performed under potential controlled conditions. In this case, optical microscopy reveals an inhomogeneous surface coverage with the formation of islands probably due to the drying step previous to the Raman experiments (not shown). The main difference between the solid dsDNA reference spectrum and that of the dsDNA immobilized at the electrode surface can be observed in Table 1. In this table we have included the bands informed in the literature, as well as the bands obtained in the case of the two types of dsDNA-modified-glassy carbon electrodes. In general, the bands of the solid dsDNA spectrum are comparable to those reported in literature. On the contrary, the number of bands corresponding to the vibrational modes of the bases decreased once the DNA is adsorbed on glassy carbon surface (either by casting or by deposition under potential controlled conditions), especially those related to guanine and adenine. This fact corroborates the strong interaction of the bases with the surface of the electrode and represents another evidence of the hydrophobic interaction of DNA with the glassy carbon surface. It is important to remark that the spectra of oligo(dG) ${ }_{21}$ and dsDNA showed similar bands and the spectra obtained before and after electrochemical oxidation of the DNA layer immobilized under potential controlled conditions, were very similar. These results suggest that the absence of guanine electrooxidation signal for a DNA immobilized on the same surface where a stripping step was previously performed (not shown), is indicative of some kind of electrode passivation by the oxidized DNA residues that remain adsorbed to the surface after the stripping step. 
Table 1. Comparison and frequency assignment between Raman bands of the solid dsDNA spectrum, taken as reference (first column), and those of the dsDNA immobilized at the electrode surface by casting the glassy carbon electrode with $10 \mu \mathrm{L}$ of $1000 \mathrm{ppm}$ dsDNA solution (second column), or by adsorbing the polynucleotide under controlled-potential conditions for full surface coverage ( $5 \mathrm{~min}$, at $0.20 \mathrm{~V}$ from a $10.0 \mathrm{ppm}$ solution) (third column), and the reference spectrum bands informed in the literature [42,43] (fourth column). Abbreviations: dA, deoxyadenosine; dT, deoxythimidine; A, adenine; T, thymine, G, guanine; bk, backbone; s, stretching; b, breathing; df, deformation; rk, rock; ip, in plane.

\begin{tabular}{|c|c|c|c|c|}
\hline $\begin{array}{l}\text { dsDNA } \\
\text { (solid) } \\
v\left(\mathrm{~cm}^{-1}\right)\end{array}$ & $\begin{array}{c}\text { dsDNA } \\
\text { (casting) } \\
v\left(\mathrm{~cm}^{-1}\right)\end{array}$ & $\begin{array}{c}\text { dsDNA } \\
\text { (potential } \\
\text { controlled } \\
\text { adsorption) } \\
v\left(\mathrm{~cm}^{-1}\right)\end{array}$ & $\begin{array}{l}\text { Literature } \\
v\left(\mathrm{~cm}^{-1}\right)\end{array}$ & Frequency assingment \\
\hline 720 & 760 & & 750 & $d T$ \\
\hline \multirow[t]{3}{*}{790} & & & 792 & $\begin{array}{c}\text { Backbone }=(b k) \\
(P-O-P)(s)\end{array}$ \\
\hline & & 890 & 896 & $\mathrm{C}_{2}^{\prime} \mathrm{H}_{2} \mathbf{r k}$ \\
\hline & 900 & & 923 & dRibose (ring) \\
\hline \multirow[t]{6}{*}{1010} & & & 1016 & $\mathrm{dT}\left(\mathrm{CH}_{3}\right.$ ip $)(\mathrm{rk})$ \\
\hline & 1070 & & 1061 & dRib (CO) (s) \\
\hline & & 1090 & 1092 & $b k(O-P-O)(s)$ \\
\hline & & 1110 & & \\
\hline & 1145 & 1145 & 1144 & native $\mathbf{d T}$ \\
\hline & & 1180 & 1182 & denatured $d T$ \\
\hline 1240 & & & 1236 & denatured $d T$ \\
\hline 1240 & 1250 & & 1256 & dA,d T \\
\hline 1300 & 1290 & & 1301 & dA,d T \\
\hline 1340 & & & 1342 & dA \\
\hline 1380 & & & 1376 & $\mathrm{dT}\left(\mathrm{CH}_{3}\right)(\mathrm{df}), \mathrm{dA}$ \\
\hline \multirow[t]{2}{*}{1410} & & & 1420 & dA, $\mathrm{C}_{5}{ }^{\prime} \mathrm{H}_{2}$ (df) \\
\hline & 1460 & 1460 & 1462 & $C_{2}^{\prime} H_{2}(d f)$ \\
\hline 1490 & & & 1483 & dA,dT \\
\hline 1590 & & & 1577 & $d A\left(N_{6} H_{2}\right)(d f)$ \\
\hline 1690 & & & 1673 & $\mathrm{C}_{4} \mathrm{O} / \mathrm{C}_{5} \mathrm{C}_{6}(\mathrm{~s})$ \\
\hline
\end{tabular}

The obvious question after these results is the feasibility to use glassy carbon modified with oligonucleotides for sequence-specific detection, since, on one hand, the DNA immobilized layer is very stable, which is highly desirable when developing a hybridization biosensor; but on the other hand, there is a strong interaction of the bases with the glassy carbon surface, that could not leave them available to recognize the complementary sequence. 
Two strategies were used to evaluate the hybridization event. One of them was based on the guanine oxidation signal and the other on the signal of a redox indicator able to preferentially bind to dsDNA. The probe was oligo(dG) $)_{21}$ while the target was oligo(dC $)_{21}$. Figure 5 shows the percentage of guanine oxidation signal as a function of the hybridization time using GCE and gCPE modified with the probe sequence. The $100 \%$ of the signal was taken from the oxidation of the probe in absence of target. The expected response, if the hybridization occurs, is a decrease in the guanine oxidation signal due to the change of the accessibility of guanine residues for the oxidation at the electrode surface. At probe-modified GCE, even after 20 min hybridization in the presence of $10.0 \mathrm{ppm}$ target, the guanine oxidation signal remained around $100 \%$. On the contrary, at probe-modified-gCPE, after 15 min hybridization the signal decreased around $60 \%$, clearly indicating that the hybridization event took place.

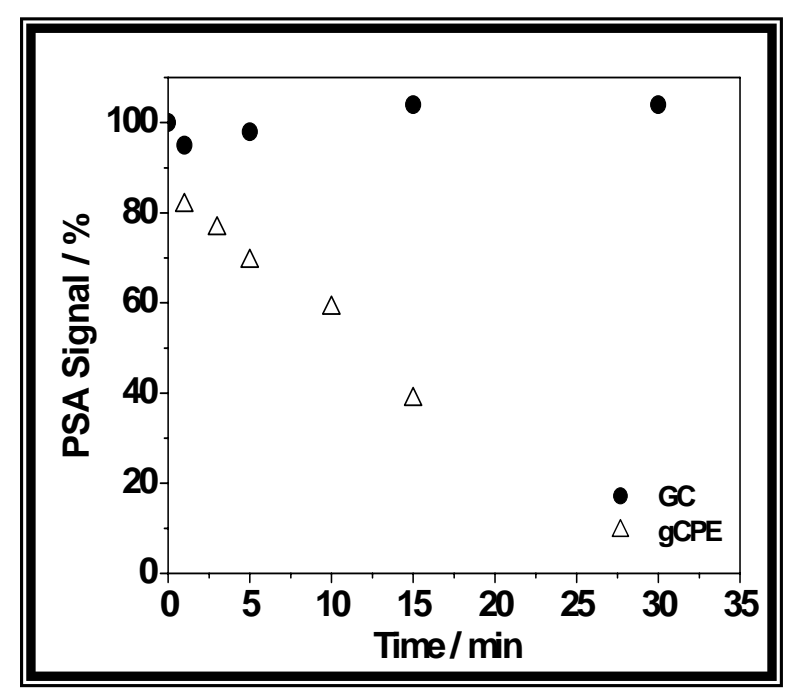

Figure 5. Chronopotentiometric guanine oxidation signal as a function of the hybridization time. The $100 \%$ corresponds to the signal obtained in the absence of complementary sequence. Probe immobilization: for GCE, $5.0 \mathrm{~min}$ at 0.200 from a $5.00 \mathrm{ppm}$ oligo(dG) $)_{21}$ and for gCPE, $10.0 \mathrm{~min}$ at $0.200 \mathrm{~V}$ from a $10.0 \mathrm{ppm}$ oligo(dG) $)_{21}$ using a pretreated gCPE (1.0 min at $1.70 \mathrm{~V}$ in the same probe solution). Hybridization conditions: different

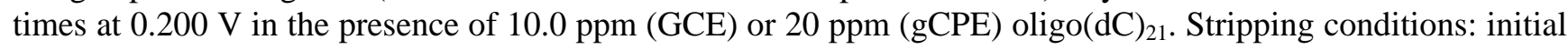
potential: $0.500 \mathrm{~V}$; current: $8.0 \mu \mathrm{A}$; solution: $0.200 \mathrm{M}$ acetate buffer $\mathrm{pH} 5.00$.

We also study the hybridization event using $\operatorname{Co}(\text { phen })_{3}{ }^{3+}$ to make sure that the expected decrease in guanine oxidation signal did not occur because the compromise of the bases in the interaction with the electrode surface and not due to problems with the electron transfer between 
guanine residues and the electrode. This redox indicator presents the advantage that the reduction occurs at very low potentials, offering, in this way, a more defined hybridization signal.

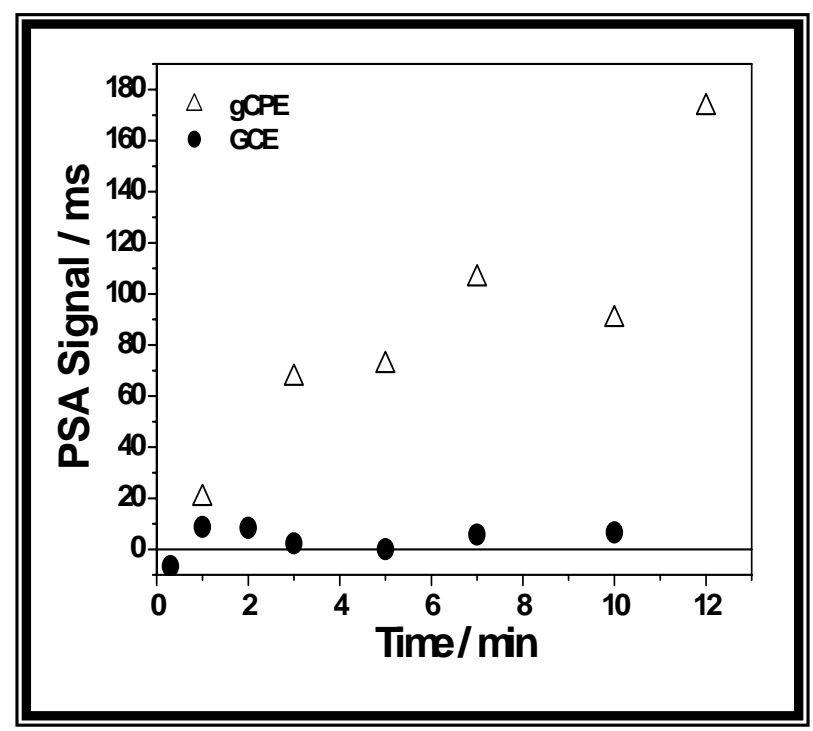

Figure 6. Chronopotentiometric signal due to the reduction of $\mathrm{Co}(\mathrm{phen})_{3}{ }^{3+}$ (obtained as the difference between the response of the redox indicator in the presence and absence of the complementary sequence) as a function of the hybridization time. The signal was taken from the difference between the reduction signal obtained in the presence and absence of the target. Probe immobilization: for GCE, $5 \mathrm{~min}$ at $0.200 \mathrm{~V}$ from a $2.00 \mathrm{ppm}$ oligo(dG) $)_{21}$ solution; for gCPE, $10 \mathrm{~min}$ at $0.20 \mathrm{~V}$ from a $5.00 \mathrm{ppm}$ oligo(dG) $)_{21}$ solution using a pretreated gCPE (1.0 min at $1.70 \mathrm{~V}$ in the same probe solution). Hybridization conditions: different times at $0.500 \mathrm{~V}$ in the presence of $1.00 \mathrm{ppm}$ oligo(dC) 21 (for GCE) and $2.50 \mathrm{ppm}$ (for gCPE). Redox indicator interaction: $2 \mathrm{~min}$ at $0.500 \mathrm{~V}$ in a $0.020 \mathrm{M}$ Tris-HCl solution $\mathrm{pH} 7.00$ containing $1.0 \times 10^{-4} \mathrm{M} \mathrm{Co}(\mathrm{phen})_{3}{ }^{3+}$. Stripping conditions: initial potential: $0.500 \mathrm{~V}$; current: - $6.0 \mu \mathrm{A}$; stripping solution: $0.020 \mathrm{M}$ Tris-HCl solution $\mathrm{pH}$ 7.00.

This redox indicator has been successfully used as hybridization redox marker [43-45]. The interaction between this metallic complex and DNA was studied at the solution [46] and at the electrode surface [47-48]. A very interesting discussion about the nature of its interaction with dsDNA immobilized at gold electrodes as a function of the ionic strength was proposed by Abruña et al. In our case, the experimental conditions for performing the interaction of the adsorbed DNA with $\mathrm{Co}$ (phen) $)_{3}{ }^{3+}$ were selected according to previous results using this redox indicator for detecting the hybridization event [43-45]. It is important to remark that in our case the dsDNA is oligo(dG) ${ }_{21^{-}}$ oligo(dC $)_{21}$, at variance with others where use calf-thymus dsDNA and the supporting electrolyte was Tris. $\mathrm{HCl}$ without $\mathrm{NaCl}$. Since this compound can interact with single stranded DNA by association at the grooves and it can also intercalate into the double helix, the analytical response was obtained as the 
difference between the signal in the presence and absence of the complementary sequence. Figure 6 shows this analytical signal as a function of the hybridization time in the presence of the target (oligo(dG) $)_{21}$ ) at probe (oligo(dC) $)_{21}$-modified GCE and gCPE. No changes in the chronopotentiometric reduction signal of $\mathrm{Co}(\text { phen })_{3}{ }^{3+}$ were observed at the GCE modified electrode, confirming that the hybridization event could not take place. At probe-gCPE the signal increases with the hybridization time due to the increase in the accumulated amount of the double helix at the surface of the electrode and the consequent increase in the amount of bond redox indicator.

In summary, considering the information given in the different publications, it is clear that if GCE is used for the detection of nucleic acids, there are several factors that need special consideration. The adsorption and further electrooxidation of DNA largely depends on the nature of the GCE, that is, on the pyrolisis conditions during the preparation. The pretreatment of the surface is another important parameter to take into account, and it is directly related to the GCE preparation conditions. In some cases a pretreatment is necessary, while in others, as in our case, is it absolutely prejudicial. As in the case of other biomolecules, the adsorption of DNA is highly dependent on the nature of the supporting electrolyte, $\mathrm{pH}$, ionic strength and the presence of halides. Acetate buffer solution, between $\mathrm{pH} 4.0$ and 5.0 have demonstrated to be a good option for adsorbing and electrooxidizing DNA, where the best response is attained with concentrations not higher than $0.200 \mathrm{M}$. The adsorption can be also done in solutions having the same (like sodium formate) or different (phosphate buffer solutions, sodium nitrate) $\mathrm{pH}$. Regarding the transduction of the signal, it is better performed in acetate buffer solution. The presence of halides changes the conformation of the nucleic acid in solution, thus, affecting the conformation in the adsorbed state, especially in the case of bromide and iodide even at very small concentrations. The results presented here, confirm that the interaction between DNA and glassy carbon electrode is mainly hydrophobic with an important compromise of the bases that decreased their availability for further hybridization.

\section{Conclusions}


The knowledge of the characteristics of the DNA layer immobilized on the surface of a transducer is critical for the adequate functioning of a biosensor. Electrochemical and spectroscopic experiments demonstrated that the interaction between DNA and glassy carbon surface is mainly hydrophobic. There is an important compromise of the bases in the adsorption, which makes difficult further hybridization. Therefore, glassy carbon is a useful electrode material to quantify DNA in a direct and very sensitive way, but not to be used for the preparation of biorecognition layers for detecting the hybridization event by direct adsorption of the probe sequence on the glassy carbon surface. It is necessary to perform some modification on the surface of this material previous to immobilize the DNA layer in order to decrease the compromise of the bases in the adsorption. Our group is currently working in this direction.

\section{Acknowledgements}

The authors want to thank Fundación Antorchas, Consejo Nacional de Investigaciones Científicas y Técnicas de Argentina (CONICET), Secretaría de Ciencia y Tecnología de la Universidad Nacional de Córdoba (SECyT-UNC), Agencia Nacional de Promoción Científica y Tecnológica (ANPCyT) and Asociación de Bioquímicos de la Provincia de Córdoba (ABC) for the financial support. M. L. P. thanks CONICET for the fellowship received. The authors want to thank Dr. Michel Mermoux and Dr. Pierre Labbé from Joseph Fourier University (Grenoble, France) for the valuable help in performing the Raman experiments in their laboratories.

\section{References and Notes}

1. Palecek, E. Oscillographic polarography of highly polymerized deoxyribonucleic acid. Nature. 1960, 188, 656-657.

2. Wang, J. From DNA biosensors to gene chips. Nucleic Acids Research. 2000, 28, 3011-3016. 
3. Pividori, M. I.; Merkoci, A.; Alegret, S. Electrochemical Genosensor Design: Immobilization of Oligonucleotides onto Transducer Surfaces and Detection Methods. Biosensors and Bioelectronics. 2000, 15, 291-303.

4. Palecek, E.; Fojta, M. DNA Hybridization and Damage. Anal. Chem. 2001,73, 75A-83A.

5. Palecek, E. Past, Present and Future of Nucleic Acids Electrochemistry. Talanta. 2002, 56, 809-819.

6. Wang, J. Electrochemical Nucleic Acid Biosensors. Anal. Chim. Acta. 2002, 469, 63-71.

7. Campas i Homs, M. DNA Sensors. Anal. Letters. 2002, 35, 1875-1894.

8. Palecek, E.; Jelen, F. Electrochemistry of Nucleic Acids and Development of DNA Sensors. Critical Reviews in Anal. Chem. 2002, 32, 261-270.

9. Fojta, M. Electrochemical Sensors for DNA Interactions and Damage. Electroanalysis. 2002, 14, 1449-1463.

10. Erdem, A.; Ozsoz, M. Electrochemical DNA Biosensors Based on DNA-Drug Interactions Electroanalysis. 2002, 14, 965-974.

11. Drummond, T. G.; Hill, M. G.; Barton, J. Electrochemical DNA Sensors. Nature Biotechnology. 2003, 21, 1192-1199.

12. Lucarelli, F.; Marrazza, G.; Turner, A. P. F.; Mascini, M. Carbon and Gold Electrodes as Electrochemical Transducers for DNA Hybridisation Sensors. Biosensors and Bioelectronics. 2004, 19, 515-530.

13. De-los-Santos-Álvarez, P.; Lobo-Castañón, M. J.; Miranda-Ordieres, A. J.; Tuñón Blanco, P. Electrochemistry of Nucleic Acids at Solid Electrodes and Its Applications. Electroanalysis. 2004, 16, 1193-1204.

14. Wang, J.; Cai, X.; Wang, J.; Jonsson, C.; Palecek, E.. Trace Measurements of RNA by Potentiometric Stripping Analysis at Carbon Paste Electrodes. Anal. Chem. 1995, 67, 4065-4070.

15. Wang, J.; Cai, X.; Jonsson, C.; Balakrishnan, M. Adsorptive Stripping Potentiometry of DNA at Electrochemically Pretreated Carbon Paste Electrode. Electroanalysis. 1996, 8, 20-24. 
16. Cai, X.; Rivas, G.; Farias, P. A. M.; Shiraishi, H.; Wang, J.; Fojta, M.; Palecek, E. Trace Measurements of Plasmid DNAs by Adsorptive Stripping Potentiometry at Carbon Paste Electrodes. Bioelectrochem. and Bioenergetics. 1996, 40, 41-47.

17. Wang, J.; Rivas, G.; Cai, X.; Chicharro, M.; Luo, D.; Palecek, E.; Nielsen, P. Adsorption and Detection of Peptide Nucleic Acids at Carbon Paste Electrodes. Electroanalysis. 1997, 9, 120-124.

18. Wang, J.; Cai, X.; Fernandes, J R.; Grant, D. H.; Ozsoz, M. Electrochemical Measurements of Oligonucleotides in the Presence of Chromosomal DNA Using Membrane-Covered Carbon Electrodes. Anal. Chem. 1997, 69, 4056-4059.

19. Wang, J.; Grundler, P.; Flechsing, G.-U.; Jasinski, M.; Rivas, G.; Sahlin, E.; Lopez, J. J. Stripping Analysis of Nucleic Acids at a Heated Carbon Paste Electrode. Anal. Chem. 2000, 72, 3752-3756.

20. Wang, J.; Cai, X.; Tian, B.; Shiraishi, H. Microfabricated Thick-film Electrochemical Sensor for Nucleic Acid Determination. Analyst. 1996, 67, 965-969.

21. Pedano, M. L.; Rivas, G. Adsorption and Electrooxidation of Carbon Nanotubes Paste Electrodes. Electrochem. Communications. 2004, 6, 10-16.

22. Wang, J.; Cai, X.; Fernandes, J. R.; Grant, D. H.; Ozsoz, M. Carbon Fiber Microelectrodes for Adsorptive Stripping Analysis of Trace Nucleic Acids. J. Electroanal. Chem. 1998, 441, 167-172.

23. Pedano, M. L.; Rivas, G. Immobilization of DNA on glassy carbon electrodes for the development of affinity biosensors. Biosensors and Bioelectronics. 2003, 18, 269-277.

24. Wang, Z.; Liu, D.; Dong, S. Study on Adsorption and Oxidation of Calf Thymus DNA at Glassy Carbon Electrode. Electroanalysis. 2000, 12, 1419-1421.

25. Wang, Z.; Liu, D.; Dong, S. In situ Infrared Spectroelectrochemical Studies on Adsorption and Oxidation of Nucleic Acids at Glassy Carbon Electrode. Bioelectrochemistry. 2001, 53, 175-181.

26. Wang, H.-S.; Ju, H.-X.; Chen, H.-Y. Voltammetric Behavior and Detection of DNA at Electrochemically Pretreated Glassy Carbon Electrode. Electroanalysis. 2000, 13, 1103-1109. 
27. Oliveira Brett, A. M.; Serrano, S. H. P.; Gutz, I.; La-Scalea, M. A. Comparison of the Voltammetric Behavior of Metronidazole at a DNA-modified Glassy Carbon Electrode, a Mercury Thin Film Electrode and a Glassy Carbon Electrode. Electroanalysis. 1997, 9, 110-114.

28. Oliveira Brett, A. M.; Serrano, S. H. P.; Gutz, I.; La-Scalea, M. A.; Cruz, M. L. Voltammetric Behavior of Nitroimidazoles at a DNA-biosensor. Electroanalysis. 1997, 9, 1132-1137.

29. Oliveira Brett, A. M.; Serrano, S. H. P.; Gutz, I.; La-Scalea, M. A. Electrochemical reduction of metronidazole at a DNA-modified glassy carbon electrode. Bioelectrochem. and Bioenergetics. 1997, 42, $175-178$.

30. Oliveira Brett, A. M.; Macedo, T. R. A.; Raimundo, D.; Marques, M. H.; Serrano, S. H. P. Electrochemical oxidation of mitoxantrone at a glassy carbon electrode. Anal. Chim. Acta. 1999, 385, 401-408.

31. Wu, K.; Fei, J.; Bai, W.; Hu, S. Direct Electrochemistry of DNA, Guanine and Adenine at a Nanostructured Film-Modified Electrode. Anal. Biochem. 2003, 376, 205-209.

32. Wang, J.; Kawde, A.-N.; Sahlin, E. Renewable pencil electrodes for highly sensitive stripping potentiometric measurements of DNA and RNA. Analyst. 2000, 125, 5-7.

33. Cai, X.; Rivas, G.; Farias, P. A. M.; Shiraishi, H.; Wang, J.; Palecek, E. Evaluation of Different Carbon Electrodes for Adsorptive Stripping Analysis of Nucleic Acids. Electroanalysis. 1996, 8, 753758.

34. Prado, C.; Flechsing, G.-U.; Grundler, P.; Foord, J. S.; Marken, F.; Compton, R. Electrochemical Analysis of Nucleic Acids at Boron-Doped Diamond Electrodes. Analyst. 2002, 127, 329-332.

35. Brabec, V.; Dryhurst, G. Electrochemical oxidation of polyadenylic acid at graphite electrodes. $J$. Electroanal. Chem. 1978, 91, 219-229.

36. Pang, D-W; Zhang, M.; Wang, Z.-L.; Qi, Y.-P.; Cheng, J. K.; Liu, Z.-Y. Modification of glassy carbon and gold electrodes with DNA. J. of Electroanal. Chem. 1996, 403, 183-188. 
37. Wang, Z.; Liu, D.; Dong, S. Study on Adsorption and Oxidation of Calf Thymus DNA at Glassy Carbon Electrode. Electroanalysis. 2000, 12, 1419-1421.

38. Oliveira Brett, A. M.; Matysik, F.- M. Voltammetric and Sonovoltammetric Studies on the Oxidation of Thymine and Cytosine at a Glassy Carbon Electrode. J. Electroanal. Chem. 1997, 429, 95-99.

39. Oliveira Brett, A. M.; Piedade, J. A. P.; Silva, L. A.; Diculescu, V. C. Voltammetric Determination of all Nucleotides. Anal. Biochem. 2004, 332, 321-329.

40. Wang, J.; Zhang, X.; Parrado, C.; Rivas, G. Controlled-release of DNA from Carbon-Paste Microelectrodes. Electrochem. Communications. 1999, 1, 197-202.

41. Zhao, Y-D.; Pang, D-W.; Hu, S.; Wang, Z-L.; Cheng, J-K.; Qi, Y-P.; Dai, H-P.; Mao, B-W.; Tian, Z-Q., Luo; J.; Lin, Z-H. DNA-modified Electrodes Part 3.: Spectroscopic Characterization of DNAmodified Gold Electrodes. Anal. Chim. Acta. 1999, 388, 93-101.

42. Movileanu, L.; Benevides, J. M.; Thomas, G. J. Jr. Temperature Dependence of the Raman Spectrum of DNA. Part I - Raman Signatures of Premelting and Melting Transitions of Poly(dAdT)·poly(dA-dT). J. Raman Spectrosc. 1999, 30, 637-649.

43. Wang, J.; Cai, X.; Rivas, G.; Shiraishi, H.; Dontha, N. ; Farias, P. A. M. DNA Electrochemical Biosensor for the Detection of Short DNA Sequences Related to the Human Immunodeficiency Virus. Anal. Chem. 1996, 68, 2629-2634.

44. Wang, J.; Rivas, G.; Cai, X.; Dontha, N.; Shiraishi, H.; Luo, D. ; Valera, F. Sequence-Specific Electrochemical Biosensing of M. tuberculosis DNA. Anal. Chim. Acta. 1997, 337, 41-48.

45. Cai, X.; Rivas, G.; Shiraishi, H.; Farias, P. A. M.; Wang, J.; Tomschik, M.; Jelen, F. ; Palecek, E. Electrochemical Analysis of Formation of Polynucleotide Complexes in Solution and at Electrode Surface. Anal. Chim. Acta. 1997, 344, 65-76.

46. Carter, M. T.; Rodriguez, M.; Bard, A. J. Voltammetric Studies of the Interaction of Metal Chelates with DNA. 2. Tris-Chelated Complexes of Cobalt (III) and Iron (II) with 1,10-Phenanthroline and 2,2'-Bipyridine. J. Am. Chem. Soc. 1989, 111, 8901-8911. 
47. Pang, D.-W.; Abruña, H. D. Micromethod for the Investigation of the Interactions between DNA and Redox-Active Molecules. Anal. Chem. 1998, 70, 3162-3169.

48. Labuda, J.; Bučková, M.; Vaničková, M.; Mattusch, J.; Wennrich, R. Voltammetric Detection of the DNA Interaction with Copper Complex Compounds and Damage to DNA. Electroanalysis. 1999, 11, 101-107.

(C) 2005 by MDPI (http://www.mdpi.org). Reproduction is permitted for noncommercial purposes. 